Tema: Materiais Cerâmicos, Compósitos e Poliméricos

\title{
CARACTERIZAÇÃO DO FOSFATO DE CÁLCIO AMORFO E FOSFATO DE CÁLCIO BIFÁSICO (BCP)*
}

\author{
Fernando Santos Souza ${ }^{1}$ \\ Thaysa Rodrigues Mendes Ferreira ${ }^{2}$ \\ Rodrigo de Oliveira Rezende ${ }^{2}$ \\ Sidney Nicodemos da Silva ${ }^{3}$ \\ Ivete Peixoto Pinheiro Silva ${ }^{4}$
}

\section{Resumo}

Estudos têm comprovado a afinidade e a eficiência do fosfato de cálcio bifásico (BCP) em aplicações médicas e odontológicas, assim como elemento adsorvente para o gás $\mathrm{CO}_{2}$, devido a sua característica de material poroso. O BCP é composto pela combinação entre hidroxiapatita (HA) e beta fosfato tricálcico ( $\beta$-TCP), na proporção usual de $2 / 3$ de HA e $1 / 3$ de $\beta$-TCP. Trata-se da mistura entre as fases solúvel, $\beta$-TCP, e estável, HA, das biocerâmicas. O BCP é obtido por meio de tratamento térmico (para cristalização) do ACP (fosfato de cálcio amorfo), na mufla, em temperaturas variando de 600 a $1300^{\circ} \mathrm{C}$, por cerca de 24 horas - calcinação. A caracterização e a comparação de amostras amorfas e amostras calcinadas, baseia-se na utilização de aparelhos DRX, MEV, FRX, difração de laser (Cilas) e análise de área superficial (BET). A seguir, na etapa de granulometria, BCP e ACP são peneirados em duas faixas de grãos: menores que $38 \mu \mathrm{m}$ e entre $53 \mu \mathrm{m}-38 \mu \mathrm{m}$. As análises por microscopia eletrônica evidenciam que o ACP possui estrutura semelhante à hidroxiapatita (HA), mas como os seus cristais são muito pequenos, essa fase aparece como amorfa. As análises por DRX indicaram a ausência de impureza cristalina distinguível nas partículas de BCP e a presença de um pico característico de $\beta$-TCP. Sabe-se que a produção de BCP demanda maior gasto energético em relação ao $A C P$, devido ao tratamento térmico (calcinação).

Palavras-chave: Síntese; Caracterização; ACP; BCP.

\section{CHARACTERIZATION OF AMORPHOUS CALCIUM PHOSPHATE AND CALCIUM PHOSPHATE BIPHASIC (BCP)}

\section{Abstract}

Studies have proven the affinity and efficiency of biphasic calcium phosphate (BCP) in medical and dental applications, as well as adsorbent for $\mathrm{CO}_{2}$ gas, due to its characteristic of porous material element. BCP is composed of a combination of hydroxyapatite (HA), and beta tricalcium phosphate ( $\beta$-TCP) in the usual ratio of $2 / 3$ of HA and $1 / 3$ of $\beta$-TCP. This is the mixing of the soluble phases $\beta$-TCP, and stable HA of bioceramics. BCP is obtained by heat treatment (crystallization) of the ACP (amorphous calcium phosphate) in the muffle furnace at temperatures, ranging from $600-1300^{\circ} \mathrm{C}$ for about 24 hours - calcination. Characterization and comparison samples and calcined amorphous samples based on the use of XRD, SEM, XRF, laser diffraction (Cilas) and analysis of surface area (BET) apparatus. Then the grading stage, BCP and ACP are sieved into two grain bands: less than $38 \mu \mathrm{m}$ and $53 \mu \mathrm{m}-38 \mu \mathrm{m}$ across. Analyses by electron microscopy show that the ACP has similar to hydroxyapatite (HA) structure, but as its crystals are very small, this phase appears as amorphous. The XRD analyzes indicated the absence of crystalline impurity distinguishable particles BCP in the presence of a characteristic peak $\beta$-TCP. It is known that the production of BCP demands higher energy consumption compared to PCA due to thermal treatment (calcination).

Keywords: Synthesis; Characterization; ACP; BCP.

1 Mestrando, Eng. de Materiais. Bolsista de mestrado, Depto. Eng, Materiais, Centro Federal de Educação Tecnológica de Minas Gerais (CEFET-MG), Belo Horizonte, MG, Brasil.

2 Graduanda, Eng. de Materiais, Depto. de Engenharia de Materiais, CEFET-MG, Belo Horizonte, MG, Brasil.

3 Doutor, Engenharia Metalúrgica e de Minas, Professor, Departamento de Engenharia de Materiais, CEFETMG, Belo Horizonte, MG, Brasil.

4 Doutora em Engenharia Metalúrgica e de Minas, Professora, Departamento de Engenharia de Materiais, CEFET-MG, Belo Horizonte, MG, Brasil.

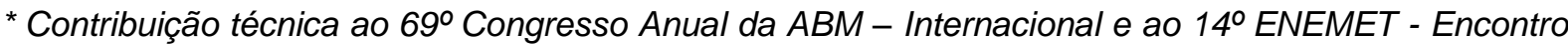
Nacional de Estudantes de Engenharia Metalúrgica, de Materiais e de Minas, 21 a 25 de julho de 


\section{INTRODUÇÃO}

\subsection{Fosfato de Cálcio}

A família de fosfato de cálcio possui a seguinte fórmula molecular $\mathrm{Ca}_{3}\left(\mathrm{PO}_{4}\right)_{2}$, foi primeiramente denominado como ortofosfato de cálcio. Enquadra-se no grupo de minerais que contém íons de cálcio $\left(\mathrm{Ca}^{2+}\right)$ em conjunto com ortofosfatos $\left(\mathrm{PO}_{4}{ }^{3-}\right)$, metafosfatos ou pirofosfatos $\left(\mathrm{P}_{2} \mathrm{O}_{7}{ }^{4-}\right)$. Na natureza, encontra-se associado ao mineral apatita e em rochas fosfato. O mineral constitui-se em geral de um pó branco e/ou ligeiramente azulado (dependendo dos elementos dopantes que alteram os seus centros de cor), sendo insolúvel em água. Além disso, o fosfato de cálcio pode também ser preparado por meio de uma mistura de soluções de íons de cálcio em presença de uma base. Dentre os fosfatos de cálcio existentes, as apatitas formam a maior parte das cerâmicas de interesse biológico e são constituídas de hidroxiapatita e de beta-fosfato tricálcico (mistura conhecida como fosfato de cálcio bifásico). O fosfato de cálcio hidratado tem uma grande susceptibilidade biológica representando até $70 \%$ em peso dos nossos ossos. Em sua maioria o tecido ósseo consiste da hidroxiapatita [Ca $\mathrm{Ca}_{10}\left(\mathrm{PO}_{4}\right)_{6}(\mathrm{OH})_{2}$, ou seja uma razão estequiométrica $\mathrm{Ca} / \mathrm{P}$ de 1,67. O esmalte dos dentes constitui-se de aproximadamente $95 \%$ de hidroxiapatita.

Os íons de cálcio $\left(\mathrm{Ca}^{2+}\right)$ são um dos principais ingredientes encontrado no leite bovino, e fundamental na ingesta humana. Além disto, as apatitas (fosfatos de cálcio) são largamente aplicadas na produção de fertilizantes e em diversos tipos de insumos industriais (da mitigação de poluentes a produção de álcoois e/ou no craqueamento de petróleo). Outro importante uso deste mineral é como fermento em alimentos. Quando adicionado a ingredientes que serão levados ao forno, ele promove a levedura do alimento (prática muito comum no preparo de pães). Além disso, também é acrescentado em alguns alimentos lácteos (como queijos), a fim de aumentar o seu valor nutricional e o teor de cálcio disponível.

Por apresentar afinidade ou semelhança química com o tecido ósseo humano possuir bioatividade e osteocondutividade. Na forma de nanopartículas dispersas os fosfatos de cálcio podem ser utilizados como veículo em sistemas biológicos como, por exemplo, para transportar ácidos nucléicos, fragmentos de vírus e/ou drogas. Esse material devido sua excelente biocompatibilidade com vários tecidos ou órgãos, induz muito pouca reação inflamatória ou imunológica (aguda ou crônica), seja ela sistêmica ou local. Desse modo, causam mínima irritação e reações alérgicas. Se adequadamente associadas aos corantes fluorescentes, tais nanopartículas podem também auxiliar na geração de imagens e na terapia fotodinâmica.

Atualmente, materiais como o ACP (fosfato de cálcio amorfo), o BCP (fosfato de cálcio bifásico), hidroxiapatita e outros membros da família do fosfato de cálcio têm sido amplamente estudados como alternativa na medicina regenerativa como forma de reparações osteocondrais. Por exemplo, os fosfatos de cálcio granulados são, hoje em dia, largamente utilizados em aplicações odontológicas voltadas aos tratamentos maxilofaciais, como a reconstituição de tecidos ósseos, a fixação de implantes e como matriz para a eliminação de defeitos ósseos.

\subsection{Fosfato de Cálcio Bifásico (BCP)}

O fosfato de cálcio bifásico constitui-se como uma biocerâmica pertencente ao grupo de biomateriais de substituição óssea. Consiste em uma mistura de hidroxiapatita

\footnotetext{
* Contribuição técnica ao 69 Congresso Anual da ABM - Internacional e ao 14 ${ }^{\circ}$ ENEMET - Encontro Nacional de Estudantes de Engenharia Metalúrgica, de Materiais e de Minas, 21 a 25 de julho de 2014, São Paulo, SP, Brasil. 


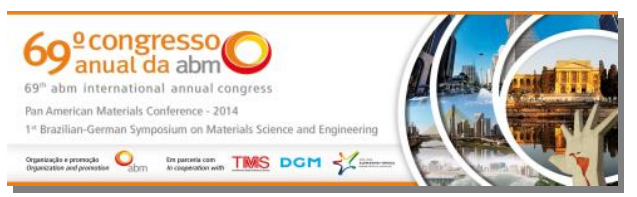

$(\mathrm{HA}),\left[\mathrm{Ca}_{10}\left(\mathrm{PO}_{4}\right)_{6}(\mathrm{OH})_{2}\right]$ e o beta fosfato tricálcico (beta-TCP), [Ca3$\left.\left(\mathrm{PO}_{4}\right)_{2}\right]$. A razão de HA/beta-TCP é variável - determinada pela deficiência de cálcio da apatita nãosinterizada (quanto maior a deficiência, menor a relação $\mathrm{Ca} / \mathrm{P}$ ) e/ou pelas temperaturas de sinterização, que promovem acima de $1100^{\circ} \mathrm{C}$ a maior ocorrência de $\beta$-TCP.

BCP é obtido quando uma apatita de origem sintética ou biológica, deficiente em cálcio, é sinterizada acima $700^{\circ} \mathrm{C}$ por cerca de 5 horas ou mais nesta temperatura. $A$ deficiência de cálcio depende do método de preparação do fosfato de cálcio amorfo (tais como pH da reação, precipitações, hidrólises, do entre outros fenômenos) que após o tratamento térmico para cristalização em temperaturas elevadas (da ordem de $1000^{\circ} \mathrm{C}$ ), levara a formação do fosfato de cálcio bifásico (sem ocorrência de sinterização) utilizado da área odonto-médica $e$ industrial. As propriedades fundamentais do BCP estão relacionadas ao seu uso em aplicações médicas envolvem a micro e a macroporosidade, razoável resistência à compressão, bioreatividade, dissolução, osteocondutividade e boa relação custo-benefício. A bioreatividade deve-se à formação de hidroxiapatita carbonatada na superfícies desta biocerâmicas tanto in vitro com in vivo, e é inversamente proporcional à razão HA/beta-TCP.

Normalmente, o uso do BCP é recomendado como alternativa ou adjuvante para ossos autógenos em aplicações ortopédicas e odontológicas, já que possui uma composição similar ao osso nativo. Encontra-se disponível sob a forma de partículas, de blocos, de desenhos personalizados em caso de aplicações específicas e, além disso, como um biomaterial injetável em um transportador de polímero.

Diversos estudos demonstram as possibilidades do uso do BCP como suporte para a Engenharia de Tecidos, para o sistema de entrega de drogas no corpo humano e, também, como veículo de fatores de crescimento. Razões de 60/40 de HA/beta-TCP, segundo estudos, resultaram em uma baixa taxa de reabsorção e foram úteis para manter enxertos autólogos.

A vantagem comparativa deste processo se deve ao fato de ser contínuo, e apresentar mínima emissão de gases de efeito estufa, baixo custo para a produção dos adsorvedores a base de apatitas (ACP ou BCP).

\section{MATERIAL E MÉTODOS}

O desenvolvimento experimental foi realizado seguindo duas etapas prédeterminadas: A produção do fosfato de cálcio amorfo $(\mathrm{ACP})$ e fosfato de cálcio bifásico (BCP) e a caracterização destes materiais. A metodologia proposta para a pesquisa consistiu na síntese e caracterização superficial do ACP e do BCP. A otimização do processo foi investigada através de uma matriz de experimento fatorial completa com as variáveis estudadas, morfologia, micro/nanoporosidade das partículas e faixa de distribuição de tamanhos.

\subsection{Materiais}

Na produção dos materiais particulados fosfato de cálcio amorfo (ACP) e fosfato de cálcio bifásico (BCP) neste estudo foi utilizada uma rota de neutralização ácidobase.

\footnotetext{
* Contribuição técnica ao 69ำ Congresso Anual da ABM - Internacional e ao 14ํㅡㄹ ENEMET - Encontro Nacional de Estudantes de Engenharia Metalúrgica, de Materiais e de Minas, 21 a 25 de julho de 


\subsubsection{Fosfato de cálcio amorfo (ACP)}

Para a produção das partículas do fosfato de cálcio amorfo (ACP) foi usado o Método Via Úmida por reação neutralização ácido-base formulada abaixo:

$10 \mathrm{Ca}(\mathrm{OH})_{2}+\mathrm{Ca}\left(\mathrm{H}_{2} \mathrm{PO}_{4}\right)_{2} . \mathrm{H}_{2} \mathrm{O} \rightarrow \mathrm{Ca}_{10}\left(\mathrm{PO}_{4}\right)_{6}(\mathrm{OH})_{2}$

A mistura das duas soluções hidratadas foi feita agitando-se a mistura até alcançar homogeneização. Após secagem foi feita a moagem da massa sólida num gral apropriado, obtendo-se o pó do ACP com granulometria variada.

\subsubsection{Fosfato de cálcio bifásico (BCP)}

O tratamento térmico do pó de ACP para obtenção do fosfato de cálcio bifásico foi feito em fornos do tipo mufla em diferentes temperaturas de 600 a $1300^{\circ} \mathrm{C}$ por tempos variando de $1 \mathrm{a} 24 \mathrm{~h}$. O material obtido após o resfriamento foi o fosfato de cálcio bifásico $(\mathrm{BCP})$ com fase majoritária a hidroxiapatita $(\mathrm{HA})$ e a fase minoritária 0 beta fosfato tricálcio $(\beta-\mathrm{TCP})$.

Foi feito um peneiramento tanto do ACP quanto do BCP utilizando as peneiras de 270 e 400 mesh, com granulometria definidas entre $38 \mu \mathrm{m}$ e $53 \mu \mathrm{m}$. Os BCPs foram submetidos previamente a determinadas operações unitárias (moagem e calcinação) para elevar sua área superficial e, portanto sua capacidade de adsorção. Ambos os materiais (ACP e BCP) têm uma distribuição de tamanho de médio $45 \mu \mathrm{m}$ e área superficial da ordem de 60 ou $10 \mathrm{~m}^{2} / \mathrm{g}$, respectivamente. O objetivo é maximizar a área superficial e funcionalizar as partículas para otimizar a capacidade de adsorção, com temperatura variando entre 20 a $70^{\circ} \mathrm{C}$, buscando possíveis aplicações industriais de forma mais seletiva.

\subsubsection{Caracterização do ACP e do BCP}

Como técnicas de caracterização físico-química do ACP e do BCP foram utilizadas a microscopia eletrônica de varredura (MEV), a difração de raios-X (DRX) e a espectroscopia de fluorescência de raios-X (FRX). Para análise da morfologia das partículas foi levado em consideração o razão de aspecto relação entre a maior e menor dimensão dos materiais particulados. As características físico-químicas como tamanho médio da partícula, superfície específica por unidade de massa e a distribuição volumétrica de poros para estes materiais particulados, foram levantados segundo as técnicas de difração de laser (CILAS) e adsorção física (BET), respectivamente. O peneirador eletromecânico utilizado no peneiramento foi o modelo I- 1016A, marca Contenco Indústria e Comércio Ltda- vibração: 0 a 100 tempo: $3 \mathrm{~min}$ a $30 \mathrm{~min}$, sendo obtidas amostras de ACP e de BCP com granulometria entre $38 \mu \mathrm{m}$ e $53 \mu \mathrm{m}$ e encaminhados para análises.

\subsubsection{Difração de raios-X (DRX)}

O DRX foi utilizado com o objetivo de se determinar as estruturas cristalinas dos pós ACP e BCP. Foi utilizado o difratômetro da marca Shimadzu, modelo XRD 7000 operado com tubo de $\mathrm{Cu}(\lambda=1,5418 \AA ̊ 冂)$, tensão de $30 \mathrm{kV}$ e corrente de $30 \mathrm{~mA}$. Os dados da curva DRX foram coletados em intervalos de varredura de 4 a $85^{\circ} \mathrm{com}$ passo de $0,02^{\circ}$ a cada $40 \mathrm{~s}$ a uma velocidade de $2^{0}$ por minuto, filtro de $\mathrm{Ni}$. As difrações obtidas foram comparadas com a base de dados ICDD (International Center for Diffration Data) para identificação das fases e cálculo do índice da cristalinidade.

\subsubsection{Microscopia eletrônica de varredura (MEV)}

Ambos os pós foram recobertos com ouro para a observação em microscópio eletrônico de varredura, marca Shimadzu, modelo Superscan SSX - 550. A

\footnotetext{
* Contribuição técnica ao 69 Congresso Anual da ABM - Internacional e ao 14 ${ }^{\circ}$ ENEMET - Encontro Nacional de Estudantes de Engenharia Metalúrgica, de Materiais e de Minas, 21 a 25 de julho de 2014, São Paulo, SP, Brasil. 


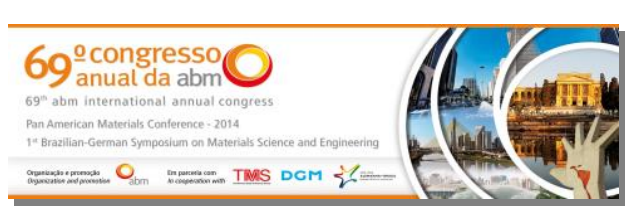

microscopia eletrônica de varredura (MEV) foi utilizada para avaliar a morfologia e a topografia dos adsorventes (ACP e BCP), obtendo-se informações sobre as partículas (razão de aspecto, distribuição de tamanho, rugosidade e porosidade). Através do microscópio eletrônico acoplado com espectrometria de energia dispersiva de raios- $X$ (EDS) foram realizadas também análises químicas dessas amostras.

Ainda foram conduzidas comparações entre medidas de tamanhos das partículas feita por MEV e as análises de distribuição granulométrica realizada por difração a laser no equipamento CILAS, modelo 1064.

As amostras foram preparadas de maneira a fosse possível tentar visualizar a estrutura externa dos adsorventes e também a estrutura interna, através da fratura dos mesmos. As micrografias dos adsorventes são mostradas e pela avaliação da topografia do material ficou evidenciada a tendência de associação dos cristais, formando aglomerados. Pode-se observar uma estrutura bastante homogênea em todo o adsorvente, com cristais, placas e material amorfo (no caso ACP) misturados uniformemente.

\subsubsection{Fluorescência de raios-X (FRX)}

A técnica de espectroscopia de fluorescência de raios $-X$ foi utilizada para análise química elementar (composição química). O equipamento utilizado no teste de fluorescência de raios- X (FRX) foi de modelo EDX - 720 da Shimadzu.

\subsubsection{Picnometria por adsorção gasosa (BET)}

A área superficial e a distribuição de poros foram medida em um picnômetro a gás Quantachrome Corporation, modelo Autosorb 1. A densidade das partículas foi medida no picnômetro, e ela se aproxima da densidade teórica da $H A\left(3,2 \mathrm{~g} / \mathrm{cm}^{3}\right)$, quando a porosidade é baixíssima.

E importante ressaltar que a porosidade total é definida como a fração de volume de poros, incluindo-se todos os poros, sejam eles conectados e não conectados, e que para efeito dos cálculos a fração em massa de poros será sempre nula. Assumindo que densidade das partículas mais poros diminui à medida que a porosidade aumenta. A partir dos resultados experimentais sobre as densidades teórica e real fornecida pelo picnômetro geram-se dados indiretos sobre a porosidade não conectada das partículas, assim, a porosidade conectada pode ser calculada pela diferença das moléculas de nitrogênio que não penetra nos poros das partículas durante ensaio. É esta porosidade aliada à reatividade química das apatitas com sua elevada área de exposição para a adsorção são os objetivos finais deste trabalho.

\section{RESULTADOS E DISCUSSÃO}

\subsection{Caracterização do ACP e do BCP}

\subsubsection{Difração de raios-X (DRX)}

Como resultado da rota de síntese utilizada (equação 1) obteve-se a transformação das matérias-primas em um fosfato de cálcio amorfo (ACP - pó sem o tratamento térmico). A Figura 2 mostra os DRXs dessas matérias-primas e do ACP, demonstrando aspectos distintos antes da reação química. O pó resultante apresenta uma cristalinidade muito baixa (inferior a 15\%). Este pó de fosfato de cálcio amorfo (ACP) foi usado ao longo deste trabalho, devido sua alta reatividade (sítios ativo, estrutura aberta e elevada área superficial), associada ainda com 0 baixo custo de obtenção ou a maior escala de produção.

\footnotetext{
* Contribuição técnica ao 69 Congresso Anual da ABM - Internacional e ao 14 ${ }^{\circ}$ ENEMET - Encontro Nacional de Estudantes de Engenharia Metalúrgica, de Materiais e de Minas, 21 a 25 de julho de 

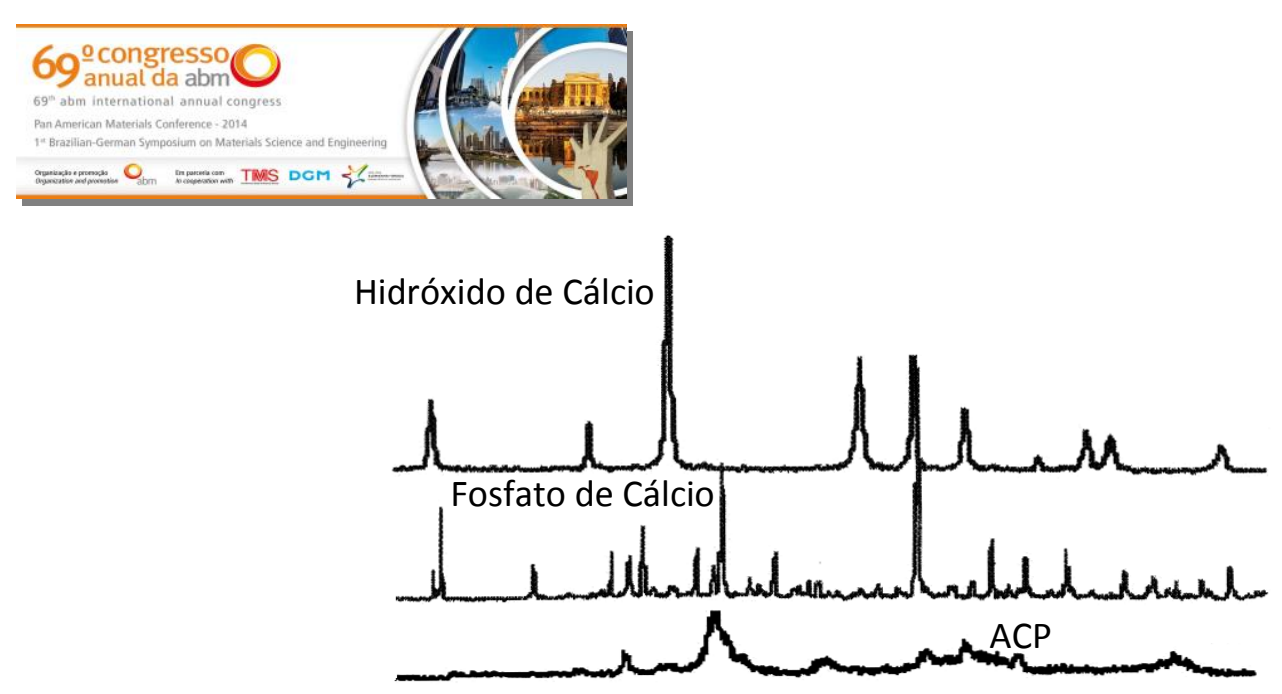

Figura 2 - DRX dos reagentes e do pó após a secagem

A literatura nos mostra que existe uma enorme variabilidade nas características físicas e químicas para essas apatitas (ou fosfato de cálcio) de origem natural ou sintética, comercialmente disponíveis no mercado. Os parâmetros ultraestruturais tais como: distribuição de tamanho de partículas, porosidade, composição química e de fases afetam sua performance. Assim a caracterização do material particulado é fundamental, uma vez que já foram evidenciadas diferenças significativas entre os muitos compostos da família dessas apatitas e sua habilidade de promover forte ligação, em especial com biomacromoléculas ou metais pesados e também efluentes diversos.

Neste estudo, a análise de DRX quantitativa foi utilizada para examinar a composição de fases do fosfato de cálcio bifásico sintetizado, como mostra a Figura 3 e r, que o perfil da difração de raios-X para o ACP, BCP e HA pura.

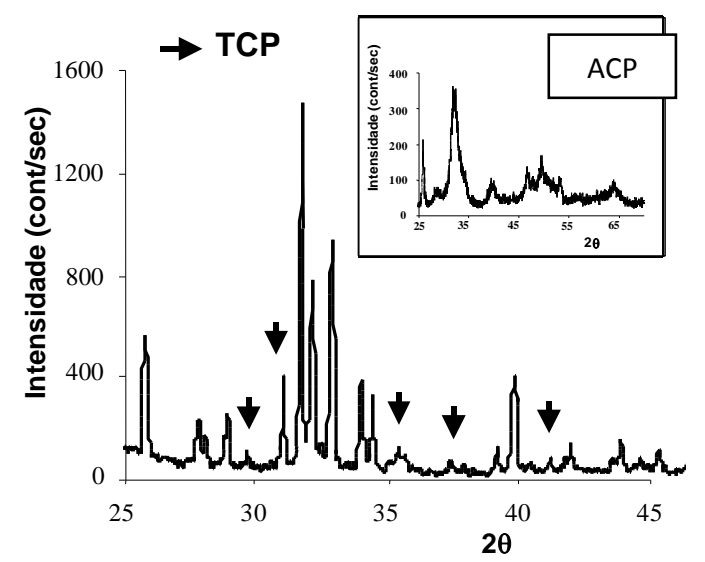

Figura 3 - Análise da difração de raios-X do BCP, seta indicando picos de $\beta$-TCP demais picos são da fase HA.
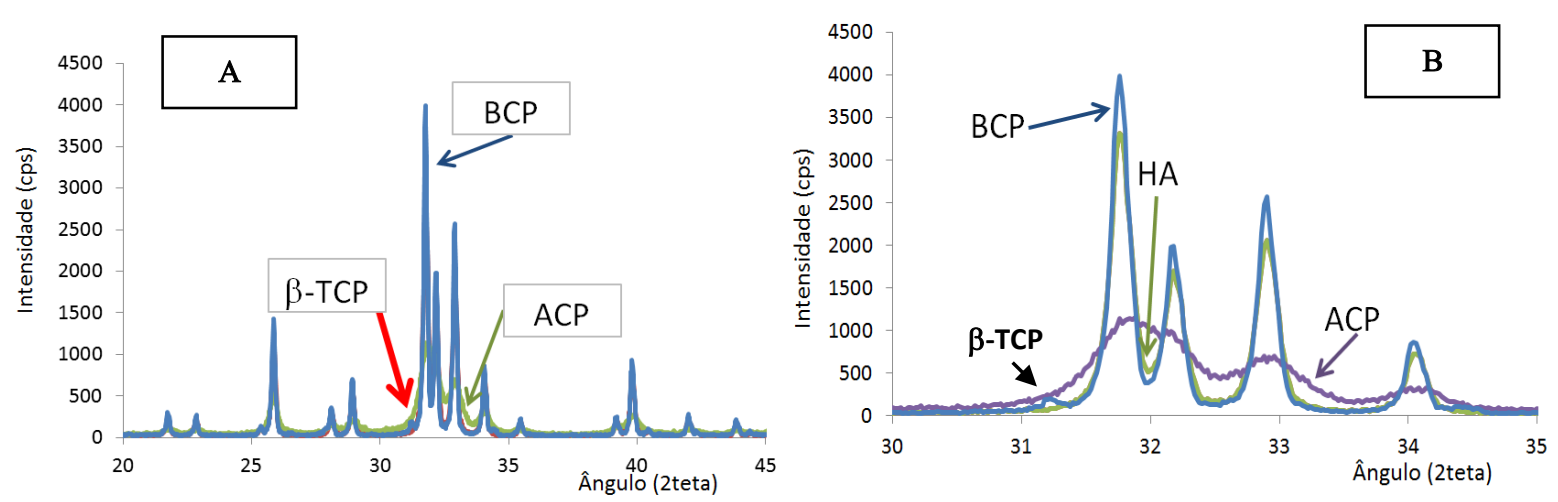

Figura 4 - (A) Análise da difração de raios-X do BCP, ACP e HA, obtidos em função das temperaturas estudadas. (B) Detalhes do DRX da amostra de ACP tratada a $700^{\circ} \mathrm{C} / 2 \mathrm{~h}$ com varredura entre 30 e 35 graus.

* Contribuição técnica ao 69 Congresso Anual da ABM - Internacional e ao 14 ${ }^{\circ}$ ENEMET - Encontro Nacional de Estudantes de Engenharia Metalúrgica, de Materiais e de Minas, 21 a 25 de julho de 2014, São Paulo, SP, Brasil. 


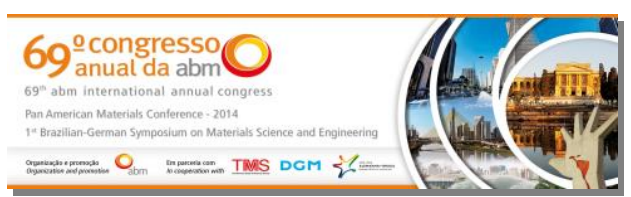

Esta figura acima mostra o padrão de difração de raio-X da amostra obtido após o tratamento de térmico. A presença de picos elevados indica um índice alto de cristalinidade (superior a 95\%). As setas apontam os picos que correspondem à presença da fase minoritária de $\beta$-TCP na amostra do BCP. As proporções de $\beta$-TCP e HA foram calculados pelo método da proporção da área abaixo dos picos cristalinos como sendo de $10 \%$ e $90 \%$, respectivamente. O inserido no canto superior direito mostra o pó ACP antes do tratamento térmico para comparação.

\subsubsection{Microscopia Eletrônica de Varredura (MEV)}

As Figuras 5 e 6 mostram aspectos morfológico e topográfico da superfície das partículas (ACP e BCP), com esses pós possuindo formatos irregulares ou pontiagudos.

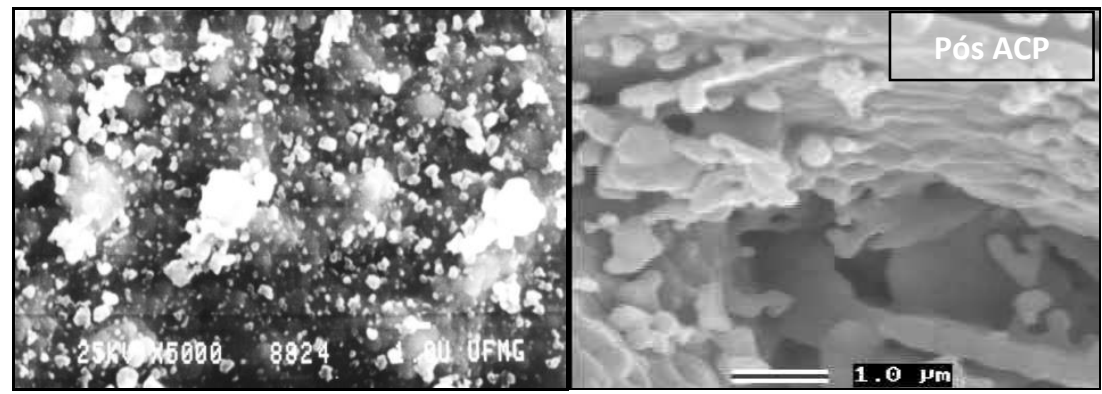

Figura 5 - Fotomicrografia de MEV com 5000X e 15000X, mostrando detalhe da

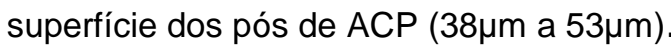

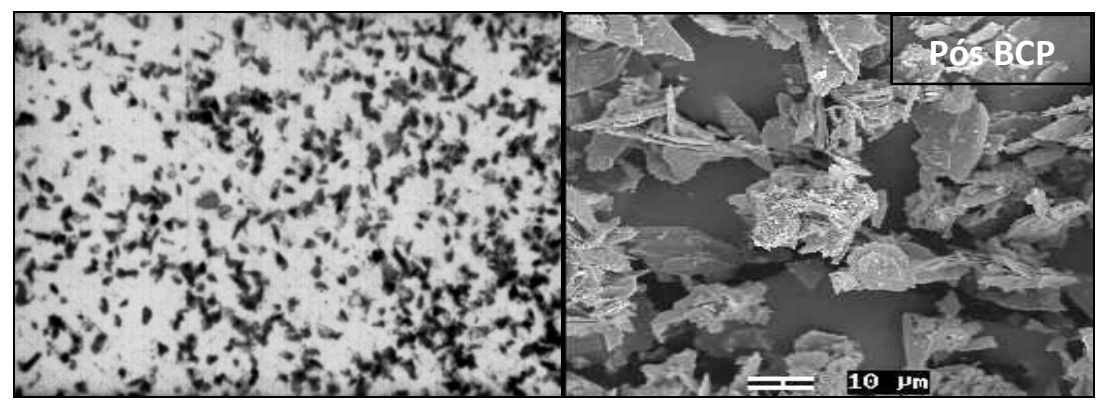

Figura 6 - Imagem de Imagem de microscópio ótico com 50 X e MEV 500 X, mostrando forma irregular dos pós de BCP $(38 \mu \mathrm{m}$ a $53 \mu \mathrm{m})$.

Através da fotomicrografias de MEV pode-se constatar que os pós tanto do ACP quanto dos BCP são constituídos por partículas e placas pequenas (coloidais) formando aglomerados com certa coesão entre estas. Em ambos os casos foram observadas partículas nanométricas aderidas às partículas maiores irregulares na forma de clusters, o que possivelmente juntamente com a porosidade também observada eleva a área superficial. A razão de aspecto varia em média de 1,5 a 2,5 indicando que a relação entre maior e menor dimensão das partículas, se afasta do formato esferoide.

A faixa de distribuição de tamanhos das partículas do ACP e do BCP obtidos no peneiramento entre $38 \mu \mathrm{m}$ e $53 \mu \mathrm{m}$ foi confirmada por medições realizadas pela técnica de difração a laser (CILAS) e também por observação no MEV.

\subsubsection{Fluorescência de raios-X (FRX)}

Como mencionado anteriormente, a composição química das fases cristalinas (HA e $\beta$-TCP) e amorfa foi confirmada pela razão estequiométrica $\mathrm{Ca} / \mathrm{P}$ e demais traços dos elementos químicos presentes nas amostras tanto pelos resultados da técnica de espectroscopia de fluorescência de raios - X (FRX), e também pela análise do EDS, durante as observações no MEV. Não observou-se o aparecimento de

* Contribuição técnica ao 69ำ Congresso Anual da ABM - Internacional e ao 14ํㅡㄹ ENEMET - Encontro Nacional de Estudantes de Engenharia Metalúrgica, de Materiais e de Minas, 21 a 25 de julho de 2014, São Paulo, SP, Brasil. 


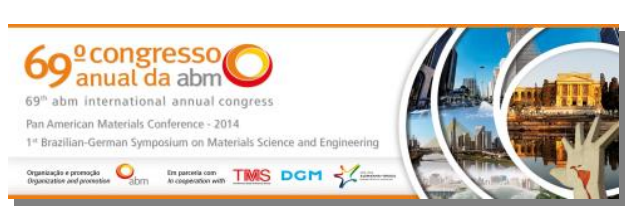

elementos químicos indesejáveis, excetos nos presentes nas matérias-primas. As duas técnicas mostram uma razão $\mathrm{Ca} / \mathrm{P}$ da mesma ordem de grandeza $(1,71 \pm 0,13)$ pelo EDS e de $(1,65 \pm 0,15)$ pelo $\mathrm{FRX}$, sendo ambos muito próximos aos valores teóricos esperados.

\subsubsection{Análise de BET}

A Tabela 1 mostra os resultados da análise de picnometria de nitrogênio, a comparação entre a distribuição de tamanhos fornecida pelo MEV e o CILAS (difração a laser), o menor tamanho dos cristalitos (nanopartículas) foi calculado cálculo através da formula de Scherrer pela DRX. Já a área superficial específica, volume e diâmetro médio de mesoporo foram determinados empregando o método BET (Brunauer, Emmett and Teller).

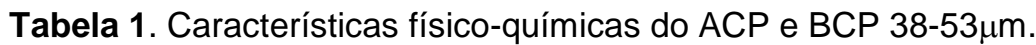

\begin{tabular}{|c|rr|rc|}
\hline & \multicolumn{2}{|c|}{ ACP } & \multicolumn{2}{c|}{ BCP } \\
\hline Tamanho Pós $(\mu \mathrm{m})$ & $\begin{array}{r}10-45 \\
0,5-44\end{array}$ & $\begin{array}{l}\text { (MEV) } \\
\text { (Laser) }\end{array}$ & $\begin{array}{r}20-50 \\
0,5-48\end{array}$ & $\begin{array}{c}\text { (MEV) } \\
\text { (Laser) }\end{array}$ \\
\hline Tamanho real da menor partícula $(\mathrm{nm})$ & \multicolumn{2}{|c|}{14} & 46 \\
\hline Área Superficial $\left(\mathrm{m}^{2} / \mathrm{g}\right)$ & \multicolumn{2}{|c|}{$67 \pm 4$} & $10 \pm 2$ \\
\hline Volume micro e mesoporos $\left(\mathrm{cm}^{3} / \mathrm{g}\right) \times 10^{-2}$ & \multicolumn{2}{|c|}{$15 \pm 3$} & \multicolumn{2}{c|}{$2,2 \pm \pm 0,5$} \\
\hline $\begin{array}{c}\text { Diâmetro médio de Micro e/ou } \\
\text { mesoporos (angstrons) }\end{array}$ & \multicolumn{2}{|c|}{$17 \pm 3$} & \multicolumn{2}{c|}{$2,2 \pm 33 \pm 2$} \\
\hline
\end{tabular}

A Tabela 1 acima fornece resultados da aplicação da técnica de adsorção de $\mathrm{N}_{2}$, obtidos diretamente dos relatórios de análise, ou então estimados a partir de dados dos mesmos. A área superficial foi calculada através da utilização da equação BET (sendo apresentada uma média entre três análises realizadas), porém deve-se salientar que o método BET com nitrogênio não fornece uma estimativa precisa para o cálculo de áreas superficiais de materiais que possuem isotermas do tipo I, por isto uma enorme dificuldade nesta determinação. Contudo, pode-se verificar que o adsorvente possui elevada área superficial e grande volume total de poros. Estes dados são importantes para interpretação dos resultados de adsorção de gasosa. Foi inicialmente identificado o tipo de isoterma e, consequentemente, a natureza do processo de adsorção. A isoterma obtida seria, à priori, do tipo I devido à presença de microporos Contudo, a inclinação positiva na curva para pressões relativa superiores a 0,5 sugerem a presença de mesoporos na estrutura deste material, levando à classificação da isoterma como do tipo I + IV .

A área superficial elevada nas amostras reforçando a observação do MEV de que os pós são constituídos de aglomerados de coloides, o que obviamente contribui para o aumento da área superficial diâmetro médio devido ao somatório das superfícies das muitas partículas finas que compõem cada cluster.

\section{CONCLUSÕES}

Observou-se, através da caracterização realizada, que o ACP e BCP possuem elevada pureza, alta superfície específica e grande volume de microporos. Os dados de parâmetros de produção e propriedades físico-químicas demonstraram experimentalmente que ambos materiais possuem elevada capacidade de adsorção, e portanto poderá ter uma boa performance seja na área da saúde, seja em aplicações industriais.

\footnotetext{
* Contribuição técnica ao 69ำ Congresso Anual da ABM - Internacional e ao 14 ENEMET - Encontro Nacional de Estudantes de Engenharia Metalúrgica, de Materiais e de Minas, 21 a 25 de julho de 


\section{Agradecimentos}

Ao apoio financeiro da FAPEMIG, concedido na forma de auxílio à pesquisa e bolsa de iniciação científica e tecnológica.

\section{BIBLIOGRAFIA}

1 Lobo SE, Arinzeh TL. Biphasic Calcium Phosphate Ceramics for Bone Regeneration and Tissue Engineering Applications. New Jersey: Materials, 2010.

2 LeGeros RZ, Lin S; Rohanizadeh R; Mijares D; LeGeros JP. Biphasic Calcium Phosphate Bioceramics: Preparation, Properties and Applications. United States: J Master Sci Mater Med, 2003.

3 Zhao J, Liu Y, Sun WB, Zhang H. Amorphous Calcium Phosphate and Its Application in Dentistry. United States: Chem Cent J., 2011.

4 Site disponível em: <http://www.wisegeek.com/what-is-calciumphosphate.htm\#didyouknowwout.> Acesso em: 22 março 2014.

5 Epple M, Ganesan K, Heumann R, Klesing J, Kovtun A, Neumann S, Sokolova V. Application of Calcium Phosphate Nanoparticles in Medicine. United States: J. Mater. Chem., 2010. 20, 18-3. 